\title{
Review: Thai Cinema: The Complete Guide, edited by Mary J. Ainslie and Katarzyna Ancuta
}

Forrest Pando

https://doi.org/10.15664/fcj.v0i17.2059

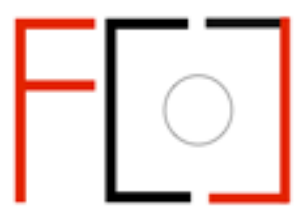

Frames Cinema Journal

ISSN 2053-8812

Issue 17 (Jun 2020)

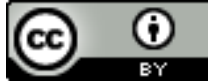

http://www.framescinemajournal.com 
Thai Cinema: The Complete Guide

\section{Edited by Mary J. Ainslie and Katarzyna Ancuta \\ I.B. Tauris, 2018 \\ Reviewed by Forrest Pando, University of St Andrews}

The fluorescent pink, blue, orange, and yellow of the cover are the first things to catch the eye of the reader of Thai Cinema: The Complete Guide. The front cover's kinetic presentation of actor Tony Jaa mid flying-knee in front of an ornamented building helps to frame the ensuing introduction in which co-editors Mary J Ainslie and Katarzyna Ancuta describe Thai cinema's explosive rise to international recognition in the early 2000s. The Complete Guide comprises ten chapters, which take readers from the beginning of Thai cinema in 1919, when the first "foreign shadows" were projected onto buildings, to the international success of independent Thai film directors in the 2010s. Between introductions to critical modes and movements, contributors review key films from these time periods and give them further context. This structure allows for a throughline which gives the reader a historical understanding of film's trajectory in Thailand and its key figures. What is in store for those drawn in by the topic is an exploration into the history and production of Thai film provided by leading experts in their fields. The Complete Guide delivers an eclectic approach to a multi-faceted film culture and history.

As promised by the front cover, the introduction highlights how Muay Thai film's international success launched Thai cinema into the global spotlight at the turn of the century. Ainslie and Ancuta go on to explain the intricacies of Thai cinema's history that could be difficult for a Western audience to grasp. For example, they address the prevalence of films a Western audience might consider genre and tonal mash-ups, as well as inconsistencies in director names and film titles between posters, end credits, and IMDB credits due to variations in phonetic spellings. Within the introduction, the co-editors express their regrets for not being able to include certain genres due to word count limitations. This is at odds with the title of the book, Thai Cinema: A Complete Guide. Despite this, their acknowledgement of this shortcoming and the care and consideration they gave to what was included speaks volumes to the editors' passion for and advocacy of Thai cinema.

In its first chapter, the book introduces ten key directors from throughout Thai cinema's history. Though informative, the reader has yet to have been introduced to a chronology of Thai cinema and therefore has no reference points with which to place these directors. One might wonder if this section could have benefitted from having been towards the end of the book as a glossary of key directors. This section's placement, as it stands, disrupts the linear flow of the following chapters.

Thai Cinema: The Complete Guide feels most at home as a companion for someone who watches a Thai film, becomes intrigued, and would like to follow that interest as far as they can. A good example of this would be if someone found Thai cinema through Ong-Bak (Prachya Pinkaew, 2003) and read this book for deeper insight and a sense of the relevant cultural connotations. Through reading Daniel Martin's film review and contextualisation, the reader would have a clearer understanding of the film's themes in relation to Thai national identity. Martin calls attention to parallels between the film and Thai life. Jaa's character, Ting, battles in a secret fight club surrounded by an entirely foreign audience. Martin explains how this echoes Thai film's underdog attempt to achieve international appeal while coming up against the reigning ubiquity of Hong 
Kong action films. Foregrounding cultural context for the reader gives them a better understanding of the film and the surrounding history.

The Complete Guide can also be helpful when coming up against difficulties with a particular film due to an absence of subtitling. In my efforts to view Dang Bireley's and Young Gangsters (Nonzee Nimibutr, 1997), a film the book recognises as invaluable to the history of Thai Cinema, I found it nearly impossible to access. When I finally did find a version I could stream online, it was peppered with ads which took up more time than the actual film and did not have English subtitles. The Complete Guide calls attention to this lack of accessibility while giving readers a roadmap of Thai Cinema, both historical and contemporary. I was able to get a general sense of what was going on within the film and the reviewer's insight acted as a contextual map for my viewing experience. The book enabled me to watch this cornerstone in Thai cinema without feeling as if its historical importance and story were lost on me.

The bulk of the book's structure relies on introduction to the historical context for a film mode or genre given by a relevant scholar. In a "show, don't tell" fashion, additional scholars continue to flesh out that history through a recounting of a film's plot, production, and critical reception. Despite the inaccessibility of many of these films, the format of the chapters makes learning about a genre or mode very easy. The Complete Guide quickly paints a broad-strokes picture of the first seventy years of Thai film. An example of this in action is Ainslie's review of $\mathrm{Ngu} P b i$ (Ratana Saetthaaphakdee, 1966), a horror film about a supernatural woman who can transform into a snake. Ainslie interprets the film's symbology by contextualising Thai anxieties about pervasive encroachment of American ideals and culture into their society and the embodiment of that through the social mobility of women post war. Ainslie touches on the cultural and historical context wrapped up in Ngu Phi's production and explains why the film is a touchstone in Thai cinema's history. The next film review, on Pisat Saneha (Pan Kam, 1969), is also written by Ainslie, and it further explains the ubiquity of the supernatural in Thai cinema and, more broadly, Thai culture. The reviews speak to each other clearly and allow a broader comprehension of the cultural and historical context of entire movements or genres.

The final two-thirds of the book feature eight chapters, which focus on the nearly twentyyear span from 1997 to 2014: New Thai Cinema, Heritage, Horror, Action, Romantic Comedy, Queer Cinema, Animation, and Independent Cinema. Similar to the early Thai Cinema section, each chapter consists of an introduction followed by reviews that give cultural context and production insight for each film. This reviewer was particularly interested in the section on independent Thai cinema, as I am well acquainted with Apichatpong Weerasethakul's readily available work. It was exciting to learn about Weerasethakul combating censorship in Thailand as well as his pursuits to support other Thai independent directors. Philippa Lovatt's effective introduction to independent Thai cinema suggests an optimistic future while grounding Thai independent cinema in its common aesthetic traits. A particular moment of clarity occurs at the end of Natalie Boehler's review of Uncle Boonme Who can Recall His Past Lives (Apichatpong Weerasethakul, 2009), where she writes "...several scenes and characters ... refer to Thai melodrama and ghost movies of the 1960s, as well as to pop culture of more recent eras". I was able to grasp Boehler's references as they were pieces of information I picked up throughout my reading of the other scholarly reviews and introductions in The Complete Guide. This was a moment when the book's throughline came together for this reviewer, and the promise of a "complete" guide began to feel warranted. 
The Complete Guide is an absolute must for anyone interested in learning more about the cinematic history of Thailand. The pedigree of scholars involved, the depth of film history and knowledge distilled, and the care and passion that clearly went into this book make it a cornerstone for further academic endeavours into Thai cinema. 